\title{
Plasma pancreatic polypeptide levels are associated with differences in body fat distribution in human subjects
}

\author{
J. Tong $\cdot$ K. M. Utzschneider $\cdot$ D. B. Carr $\cdot$ S. Zraika • \\ J. Udayasankar • F. Gerchman • R. H. Knopp • \\ S. E. Kahn
}

Received: 17 July 2006 / Accepted: 6 November 2006 / Published online: 15 December 2006

(C) Springer-Verlag 2006

\begin{abstract}
Aims/hypothesis Pancreatic polypeptide (PP) is produced by the F-cells of the pancreas, and its plasma concentration has been used as a marker of parasympathetic activity. Recent work in rodents suggests that there is both sympathetic and parasympathetic innervation of white adipose tissue and that parasympathetic activity is anabolic resulting in lipid accumulation. We have examined whether in humans increased PP levels are associated with increased intra-abdominal fat (IAF), and thereby insulin resistance. Materials and methods We measured PP levels in 177 nondiabetic subjects (75 male/102 female; age 32-75 years) 3 min after an i.v. glucose bolus during a frequently sampled intravenous glucose tolerance test. IAF and s.c. fat (SCF) areas were measured by CT scan. The insulin sensitivity index $\left(S_{\mathrm{I}}\right)$ was quantified using Bergman's minimal model.

Results PP levels were higher in men than in women (96.2 \pm 72.2 vs $76.1 \pm 55.0 \mathrm{pg} / \mathrm{ml}$, mean $\pm \mathrm{SD}, p=0.037)$, as was IAF area $\left(124.7 \pm 67.4\right.$ vs $\left.83.0 \pm 57.7 \mathrm{~cm}^{2}, p<0.001\right)$. While PP

J. Tong $\cdot$ K. M. Utzschneider $\cdot$ S. Zraika $\cdot$ J. Udayasankar •

F. Gerchman • R. H. Knopp · S. E. Kahn

Division of Metabolism, Endocrinology and Nutrition,

Department of Medicine, VA Puget Sound Health Care System,

Harborview Medical Center and University of Washington,

Seattle, WA, USA

D. B. Carr

Department of Obstetrics and Gynecology,

University of Washington,

Seattle, WA, USA

J. Tong $(\bowtie)$

VA Puget Sound Health Care System (151),

1660 South Columbian Way,

Seattle, WA 98108, USA

e-mail: tongj@u.washington.edu
\end{abstract}

levels were significantly associated with IAF $(r=0.16, p=$ $0.031)$, WHR $(r=0.30, p<0.001)$ and age $(r=0.37, p<0.01)$, they were not associated with SCF $(r=0.02, p=0.829)$. The association between PP and IAF was not independent of age and/or sex. $S_{\mathrm{I}}$ was negatively associated with PP levels $(r=-0.17, p=0.026)$ and IAF area $(r=-0.65, p<0.001)$. The association between $S_{\mathrm{I}}$ and PP disappeared after adjusting for IAF area, indicating that $S_{\mathrm{I}}$ was not a major determinant of PP levels.

Conclusions/interpretation In humans, age and sex may modulate the association between plasma PP level and IAF area, suggesting that they may be determinants of parasympathetic activity and thus IAF accumulation.

Keywords Insulin resistance - Pancreatic polypeptide .

Parasympathetic nervous system $\cdot$ Visceral fat

\begin{tabular}{|c|c|}
\hline \multicolumn{2}{|c|}{ Abbreviations } \\
\hline AIRg & acute insulin response to glucose \\
\hline FSIGT & $\begin{array}{l}\text { frequently sampled intravenous glucose } \\
\text { tolerance test }\end{array}$ \\
\hline IAF & intra-abdominal fat \\
\hline PP & pancreatic polypeptide \\
\hline $\mathrm{SCF}$ & subcutaneous fat \\
\hline $\mathrm{Sg}$ & glucose effectiveness at basal insulin \\
\hline $\mathrm{S}_{S}$ & insulin sensitivity index \\
\hline
\end{tabular}

\section{Introduction}

Abdominal obesity and insulin resistance are important factors contributing to the pathogenesis of type 2 diabetes and the metabolic syndrome. Epidemiological studies have 
suggested that abdominal obesity precedes the development of insulin resistance [1]. However, the mechanism for intraabdominal fat (IAF) accumulation in humans has not been elucidated.

Previous animal studies have shown that the CNS is an important regulator of body fat distribution and insulin secretion. Kreier et al. [2] demonstrated that parasympathetic input to adipose tissue modulated insulinmediated glucose uptake and NEFA metabolism to facilitate uptake and storage of nutrients. These findings led to speculation that parasympathetic output may modulate the accumulation of adipose tissue in specific compartments [2].

Pancreatic polypeptide (PP) is produced by the endocrine F-cells in the pancreatic islets. Intracerebroventricular administration of PP has orexigenic effects in mice while peripheral administration reduces food intake in both rodents and humans [3, 4]. PP secretion is regulated by food intake, glucose, gastrointestinal hormones and neuropeptides, but cholinergic vagal stimulation is the most powerful stimulatory mechanism. In the basal state, PP secretion is partially under control of cholinergic tone, probably related to vagal tone, since PP concentrations are also reduced by vagotomy. Therefore, the plasma concentration of PP has been used as an indirect marker of parasympathetic activity [5].

We hypothesised that in humans increased plasma PP levels are associated with increased IAF in healthy subjects and that the relationship between PP levels and insulin sensitivity would be determined in part by IAF.

\section{Subjects and methods}

\section{Study design}

We conducted a cross-sectional study of 177 apparently healthy subjects (75 male/102 female; age 32-75 years), with no history of diabetes, dyslipidaemia or uncontrolled hypertension. Further exclusion criteria were fasting plasma glucose $\geq 6.4 \mathrm{mmol} / \mathrm{l}$, biochemical evidence of liver or renal disease, coronary or other vascular disease and anaemia [6]. All subjects provided written informed consent, and the study was reviewed and approved by the Human Subjects Review Committee at the University of Washington.

\section{Anthropometry and body fat measures}

Waist and hip circumferences were measured using the NHANES III Anthropometric Measurements protocol [6]. Height and weight were measured and BMI was calculated. The average of two measurements was used.
IAF and subcutaneous fat (SCF) areas were measured by a single-slice CT scan at the level of the umbilicus as previously described [6].

Insulin sensitivity and insulin release

The insulin sensitivity index $\left(S_{\mathrm{I}}\right)$, glucose effectiveness at basal insulin $(\mathrm{Sg})$ and the acute insulin response to glucose (AIRg) were determined from a frequently sampled, tolbutamide-modified intravenous glucose tolerance test (FSIGT) using $11.4 \mathrm{~g} / \mathrm{m}^{2}$ of glucose and $125 \mathrm{mg} / \mathrm{m}^{2}$ of tolbutamide as previously described [6].

Assay

Plasma PP concentrations were measured after an overnight fast of at least $12 \mathrm{~h}$, using the 3-min sample from the FSIGT due to lack of adequate volume from the fasting sample. In a pilot study in 20 pre-menopausal healthy female volunteers (25\% obese), PP levels 3 min after i.v. glucose administration were $44.7 \pm 11.3$ vs $51.1 \pm 17.1 \mathrm{pg} / \mathrm{ml}$ prior to glucose $(p=0.02)$, with the values at the two timepoints highly correlated $(r=0.93)$. The change in PP levels did not differ between obese and non-obese subjects (7.2 \pm 3.2 vs $3.8 \pm 0.73, p=0.55)$ and was not associated with age $(r=0.11, p=0.68)$ or IAF $(r=-0.57, p=0.09)$. Plasma PP was quantified using an RIA (Linco, St Charles, MO, USA). The intra-assay variation for PP was $7 \%$ and interassay variation was $10 \%$.

Statistical analysis

Unpaired $t$ tests were used to compare mean values between groups. Associations between PP level and $S_{\mathrm{I}}$, IAF area and other variables of interest were examined using simple or multiple linear regression analysis. Data that were not normally distributed were transformed to achieve normal distribution. Data are presented as mean \pm SD unless otherwise specified. A two-sided $p<0.05$ was considered statistically significant.

\section{Results}

\section{Subject characteristics}

Subjects had wide ranges of BMI $\left(18.4-46.7 \mathrm{~kg} / \mathrm{m}^{2}\right), S_{\text {I }}$ $\left(0.7 \times 10^{-5}-30.0 \times 10^{-5} \mathrm{~min}^{-1} /[\mathrm{pmol} / \mathrm{l}]\right)$ and PP levels $(14$ $350 \mathrm{pg} / \mathrm{ml}$ ) (Table 1). Men had higher mean IAF area, waist circumference and fasting glucose than women, while women had higher SCF area and HDL-cholesterol than men (Table 1). Eighteen per cent (32/177) of the subjects were obese. 
Table 1 Baseline characteristics (means \pm SD) of the study population

\begin{tabular}{llll}
\hline & Male & Female & Total \\
\hline$n$ & 75 & 102 & 177 \\
Age $($ years $)$ & $52.6 \pm 10.5$ & $52.4 \pm 9.8$ & $52.5 \pm 10.0$ \\
BMI $\left(\mathrm{kg} / \mathrm{m}^{2}\right)$ & $26.8 \pm 3.5$ & $26.1 \pm 4.8$ & $26.4 \pm 4.3$ \\
Waist circumference $(\mathrm{cm})$ & $95.0 \pm 10.6^{*}$ & $81.7 \pm 12.3$ & $87.2 \pm 13.3$ \\
WHR & $0.91 \pm 0.06$ & $0.78 \pm 0.06$ & $0.84 \pm 0.09$ \\
IAF area $\left(\mathrm{cm}^{2}\right)$ & $124.7 \pm 67.4^{*}$ & $83.0 \pm 57.7$ & $100.7 \pm 65.2$ \\
SCF area $\left(\mathrm{cm}^{2}\right)$ & $184.0 \pm 87.8^{*}$ & $243.0 \pm 133.1$ & $218.0 \pm 119.4$ \\
$S_{\mathrm{I}}\left(\times 10^{-5} \mathrm{~min}^{-1} /[\mathrm{pmol} / \mathrm{l}]\right)$ & $5.9 \pm 4.4$ & $6.7 \pm 3.9$ & $6.4 \pm 4.1$ \\
Fasting glucose $(\mathrm{mmol} / \mathrm{l})$ & $5.6 \pm 0.4^{*}$ & $5.3 \pm 0.4$ & $5.4 \pm 0.4$ \\
Fasting insulin $(\mathrm{pmol} / \mathrm{l})$ & $64.3 \pm 36.6$ & $62.2 \pm 40.9$ & $63.1 \pm 39.0$ \\
Total cholesterol $(\mathrm{mmol} / \mathrm{l})$ & $5.1 \pm 0.8$ & $5.2 \pm 0.9$ & $5.2 \pm 0.9$ \\
Triacylglycerol $(\mathrm{mmol} / \mathrm{l})$ & $1.4 \pm 1.0$ & $1.3 \pm 0.8$ & $1.4 \pm 0.9$ \\
LDL-cholesterol $(\mathrm{mmol} / 1)$ & $3.3 \pm 0.7$ & $3.2 \pm 0.7$ & $3.2 \pm 0.7$ \\
HDL-cholesterol $(\mathrm{mmol} / \mathrm{l})$ & $1.1 \pm 0.2^{*}$ & $1.5 \pm 0.4$ & $1.3 \pm 0.3$ \\
PP (pg/ml) & $96.2 \pm 72.2 *$ & $76.1 \pm 55.0$ & $84.6 \pm 63.4$ \\
\hline
\end{tabular}

${ }^{*} p<0.05$ vs female

Relationships between PP levels and sex, age, body fat measures and insulin sensitivity

PP levels were higher in men than in women and were positively associated with age $(r=0.37, p<0.001)$.

PP levels did not differ between obese and non-obese individuals (BMI $\left.<30 \mathrm{~kg} / \mathrm{m}^{2}\right)(101.7 \pm 84.6$ vs $80.9 \pm 57.4$, $p=0.092$ ), even after adjusting for sex and age. PP levels were significantly associated with IAF area (Table 2, model 1) but not SCF area $(r=0.02, p=0.829)$ or BMI $(r=0.04$, $p=0.605$ ). The association between PP and IAF disappeared after adjusting for age or sex (Table 2, models 2 and 3). PP was significantly associated with IAF:SCF ratio and WHR (Table 2, models 4 and 7), which also disappeared after adjusting for age and/or sex (Table 2, models 5, 6 and $10)$.

By simple regression analysis, PP was negatively associated with $S_{\text {I }}$ (Table 2, model 11). This association was independent of sex (Table 2, model 13), but not age or IAF (Table 2, models 12 and 14). No association was observed between PP and fasting insulin levels. As expected, $S_{\mathrm{I}}$ was negatively associated with IAF area $(r=-0.65, p<0.001)$.

PP levels were not associated with $\mathrm{Sg}(r=-0.05$, $p=0.51)$ or AIRg $(r=0.08, p=0.28)$.

\section{Discussion}

We found that PP levels are higher in men and increase with age. We also demonstrated that they were higher in subjects with greater amounts of visceral adiposity, but were not related to BMI or SCF. This association between
Table 2 Association between IAF area or IAF/SCF ratio or WHR or $S_{\text {I }}$ (dependent variables) and PP levels (independent variable) while adjusting for age or sex

\begin{tabular}{|c|c|c|}
\hline Dependent and independent variable & $r$ & $p$ \\
\hline \multicolumn{3}{|l|}{ Dependent variable: IAF area } \\
\hline \multicolumn{3}{|l|}{ Independent variable } \\
\hline \multicolumn{3}{|l|}{ Model 1} \\
\hline $\mathrm{PP}$ & 0.16 & 0.031 \\
\hline \multicolumn{3}{|l|}{ Model 2} \\
\hline $\mathrm{PP}$ & 0.08 & 0.306 \\
\hline Age & 0.20 & 0.009 \\
\hline \multicolumn{3}{|l|}{ Model 3} \\
\hline PP & 0.12 & 0.121 \\
\hline Sex & -0.32 & $<0.001$ \\
\hline \multicolumn{3}{|l|}{ Dependent variable: IAF/SCF } \\
\hline \multicolumn{3}{|l|}{ Independent variable } \\
\hline \multicolumn{3}{|l|}{ Model 4} \\
\hline $\mathrm{PP}$ & 0.17 & 0.028 \\
\hline \multicolumn{3}{|l|}{ Model 5} \\
\hline PP & 0.09 & 0.223 \\
\hline Age & 0.20 & 0.007 \\
\hline \multicolumn{3}{|l|}{ Model 6} \\
\hline $\mathrm{PP}$ & 0.11 & 0.151 \\
\hline Sex & -0.59 & $<0.001$ \\
\hline \multicolumn{3}{|l|}{ Dependent variable: WHR } \\
\hline \multicolumn{3}{|l|}{ Independent variable } \\
\hline \multicolumn{3}{|l|}{ Model 7} \\
\hline $\mathrm{PP}$ & 0.30 & $<0.001$ \\
\hline \multicolumn{3}{|l|}{ Model 8} \\
\hline $\mathrm{PP}$ & 0.22 & 0.005 \\
\hline Age & 0.19 & 0.017 \\
\hline \multicolumn{3}{|l|}{ Model 9} \\
\hline PP & 0.23 & 0.003 \\
\hline Sex & -0.72 & $<0.001$ \\
\hline \multicolumn{3}{|l|}{ Model 10} \\
\hline $\mathrm{PP}$ & 0.11 & 0.152 \\
\hline Age & 0.31 & $<0.001$ \\
\hline Sex & -0.73 & $<0.001$ \\
\hline \\
\hline \multicolumn{3}{|l|}{ Independent variable } \\
\hline \multicolumn{3}{|l|}{ Model 11} \\
\hline PP & -0.17 & 0.026 \\
\hline \multicolumn{3}{|l|}{ Model 12} \\
\hline PP & -0.11 & 0.141 \\
\hline Age & -0.12 & 0.122 \\
\hline \multicolumn{3}{|l|}{ Model 13} \\
\hline PP & -0.15 & 0.047 \\
\hline Sex & 0.10 & 0.175 \\
\hline \multicolumn{3}{|l|}{ Model 14} \\
\hline $\mathrm{PP}$ & -0.08 & 0.267 \\
\hline IAF & -0.62 & $<0.001$ \\
\hline
\end{tabular}

PP and visceral adiposity was dependent on age and sex. Further, the inverse relationship between PP and insulin sensitivity appears to be mediated by IAF and age.

The mechanism(s) responsible for IAF accumulation remains to be elucidated. Age and male sex are associated 
with increased visceral adiposity [6] and both affect autonomic nervous system and hypothalamic function [7]. In the current study we observed similar associations to those previously described between age, sex and IAF. We confirmed that PP levels are higher in men and in older subjects [8]. It is intriguing, based on these similar observations, to speculate that the differential age and sex effects on IAF accumulation may be mediated through parasympathetic activity.

Another interesting observation was that while IAF area and plasma PP were related, no association between PP and SCF area was present. Kreier et al. demonstrated that IAF and SCF were innervated by separate sympathetic and parasympathetic motor neurons in rats, and that fat padspecific vagotomy shifted metabolism to a catabolic state [2]. These findings suggest that CNS control of adipose tissue may be through selective control of sympathetic and parasympathetic output to a specific adipose site. Thus, misbalanced autonomic outflow to visceral fat may be an important factor in its pathogenesis.

The relationship between PP levels and insulin sensitivity has been studied in Pima Indians. Fasting levels were higher in age- and sex-matched Pima Indian compared with white children, but not different in adults. In response to a mixed meal, Pima Indians had markedly higher PP responses than whites. Fasting PP levels were positively associated with fasting insulin in both adults and children [9]. However, another study in Pima Indian men with normal glucose tolerance demonstrated that parasympathetic blockade attenuated the early postprandial response in PP but did not similarly affect insulin, suggesting that hyperinsulinaemia in this ethnic group is not mediated via increased islet parasympathetic tone [10]. Our finding of an inverse relationship between insulin sensitivity and PP levels suggests that there may be a potential role of increased parasympathetic tone in the presence of insulin resistance. However, this association disappeared after adjusting for IAF or age, suggesting that this association may be mediated by IAF and/or age. Therefore, we believe that collectively the data suggest that enhanced parasympathetic activity, manifest as increased PP levels, is unlikely to play a major direct role in mediating insulin sensitivity.

One limitation of our study is that we measured PP levels using a sample obtained $3 \mathrm{~min}$ after i.v. glucose administration and the difference was not related to age or obesity. However, as discussed, we found a strong inverse $(r=-0.57)$, albeit borderline-significant $(p=0.09)$, association between IAF area and the change (reduction) in PP level following i.v. glucose in a pilot study of 20 subjects. Therefore, we cannot exclude the possibility that the use of a post-glucose load sample may have contributed to our results.

In conclusion, we found that fasting PP levels are related to visceral fat area, suggesting that parasympathetic control of this depot may be important, and that age and sex may mediate this relationship. Additional work utilising fasting and post-meal challenge PP measurements appears warranted in order to provide further insight into the role of parasympathetic innervation in determining body fat distribution.

Acknowledgements This study was supported by the Department of Veteran Affairs, American Egg Board, NIH Grants DK-02456, DK02654, DK-17047, DK-35747, DK-35816, DK-59417, HL-30086, HL-07028, and RR37, the US Department of Agriculture, McMillen Family Trust and the American Diabetes Association.

Duality of interest No author has an interest in or relationship with a company/organisation that could benefit financially from the publication of the data in this paper.

\section{References}

1. Despres JP (2006) Is visceral obesity the cause of the metabolic syndrome? Ann Med 38:52-63

2. Kreier F, Fliers E, Voshol PJ et al (2002) Selective parasympathetic innervation of subcutaneous and intra-abdominal fatfunctional implications. J Clin Invest 110:1243-1250

3. Asakawa A, Inui A, Ueno N, Fujimiya M, Fujino MA, Kasuga M (1999) Mouse pancreatic polypeptide modulates food intake, while not influencing anxiety in mice. Peptides 20:1445-1448

4. Batterham RL, Le Roux CW, Cohen MA et al (2003) Pancreatic polypeptide reduces appetite and food intake in humans. J Clin Endocrinol Metab 88:3989-3992

5. Schwartz TW (1983) Pancreatic polypeptide: a unique model for vagal control of endocrine systems. J Auton Nerv Syst 9:99-111

6. Cnop M, Landchild MJ, Vidal J et al (2002) The concurrent accumulation of intra-abdominal and subcutaneous fat explains the association between insulin resistance and plasma leptin concentrations: distinct metabolic effects of two fat compartments. Diabetes 51:1005-1015

7. Esler MD, Turner AG, Kaye DM et al (1995) Aging effects on human sympathetic neuronal function. Am J Physiol 268:R278R285

8. Brimnes Damholt M, Rasmussen BK, Hilsted L, Jensen R, Hilsted $\mathrm{J}$ (1997) Basal serum pancreatic polypeptide is dependent on age and gender in an adult population. Scand $\mathrm{J}$ Clin Lab Invest 57:695-702

9. Weyer C, Salbe AD, Lindsay RS, Pratley RE, Bogardus C, Tataranni PA (2001) Exaggerated pancreatic polypeptide secretion in Pima Indians: can an increased parasympathetic drive to the pancreas contribute to hyperinsulinemia, obesity, and diabetes in humans? Metabolism 50:223-230

10. Vozarova de Courten B, Weyer C, Stefan N et al (2004) Parasympathetic blockade attenuates augmented pancreatic polypeptide but not insulin secretion in Pima Indians. Diabetes 53:663-671 